\title{
Preface
}

\section{STUDIES IN RISK MANAGEMENT EXAMPLES OF CALCULATION OF THE VALUE DEDUCTED}

\author{
by Orio Giarini
}

\section{Between Scylla and Charybdis}

There can be no doubt about the potential for progress represented by electronic data processing and containerisation in transport systems. They are an irreplacable tool which modern science and technology have placed in the hands of our society and economy.

But the path of any progress, technological or other, is often dangerous and strewn with obstacles. Taking it is a little like repeating the odyssey of Ulysses who, after the Trojan war, only reached home after many adventures and departures from his course.

The modern world increasingly requires this ability to steer, which nowadays is called management. The land and sea routes of the past involved tackling the unknown and taking risks ; to these the modern world has added a steadily growing number of new routes and of new risks. We have given a greater dimension to everything, including uncertainty.

The vessel of science and technology, in particular, seems destined to sail forever between Scylla and Charybdis. On one side, it is drawn towards those who never abandon the hope of taking their revenge on science and technology, seeking a world where man is left to the hazards of his irrational impulses and his limited biological resources; they refuse to aim any higher.

On the other side - and these dangers are sometimes less easy to discern - the vessel is drawn towards those on the opposite shore who tend to treat science and technology as a magic feature of our cultural and economic life. In their case, science and technology have become religions and are "believed in" far more than they are understood. The result is that people expect miracles like the "water-powered" motor car which will rule out another oil supply crisis in a year or two, nuclear fusion on a large scale in the next decade and - why not? - a " really intelligent computer".

For the former group, the computers, containers or any other modern technology should never have been invented.

For the latter, "all we have to do " is to give to any technology its head so that it can perform its miracles. But this attitude merely paves the way for the kind of hostile reactions that are bound to occur when mishaps prove that science and technology are circumscribed by man's own limitations and have no supernatural powers. The inevitable disappointment with the new idols ends by harming true science and by making feasible technological development more difficult. 
Although on opposite sides, Scylla and Charybdis lead to the same result: shipwreck.

For this reason, it is very important to give a broader interpretation to the surveys presented here. If we are not to come to grief on either Scylla or Charybdis, we must ensure that such important developments as electronic data processing or containerisation avoid the reefs of misunderstanding, whether those of subborn rejection or of naive enthusiasm. And we must also understand why the costs of fire seem to grow more than proportionally to the growth of National Income and represent already $1 \%$ of it.

\section{The quantification of value deducted}

Every technological and economic development must be reflected in a real advance in well-being and/or knowledge.

One of the major drawbacks of economic theory has been its inability to integrate adequately the process of scientific discovery and of technological innovation into its models and theories.

The result has been that for too long it was believed that growth in economic activity, measured in the form of gross added value and equivalent to a rise in output, was the same thing as an improvement in material well-being (hence the concept of living standards reflected in the index of the national income).

This latter assumption, which we consider to be false, arises out of a misunderstanding of the process leading from scientific discovery to technological invention and its effects on the economy - economists in recent decades have tended to be naive admirers of technology, after having previously ignored it almost completely. Critical economic analysis of the process of discovery and invention shows that the phenomenon of diminishing returns also applies to technology and it is essential to allow for this in any economic model as well as in the production function ${ }^{1}$.

The studies published in this issue are an example of what might be called the quantification of the "value deducted". The several billions of dollars of annual losses expected in the next decade and caused by the use of computers and containers in Europe and in the world as well as the global costs of fire represent an example of this value deducted. After all, the net value added produced by the data-processing sector and by containerisation will only represent a real improvement in material well-being to the extent that the value or cost of its negative effects is deducted.

This value deducted, which is quite substantial in absolute terms, is still an acceptable percentage of the added value. But in the longer term, in accordance with the concept of the entropy of the economic process described by Georgescu-Roegen, it will be necessary to watch very closely the tendency of the value deducted to rise more rapidly than the relevant gross added value, as we can see when, for instance,

1 See "Etudes et Dossiers" No. 3, "Information Letter" No. 19 of the "Geneva Association", and "The Geneva Papers on Risk and Insurance" No. 6. The ideas proposed in these texts have been further elaborated and published in a book: "The diminishing returns of technology" (Pergamon Press, Oxford, 1978; French edition by Dunod, Paris, 1979, and Italian edition by Mondadori-Est, Milan, 1978). 
the expected traffic growth in containerisation up to 1988 is estimated at $100 \%$ against a damages growth of $150 \%$. There is a whole new field here for economic research.

We cannot develop this theme here, but it is perhaps worth emphasising that the distinction between value added and value deducted makes it possible, first of all, for economic analysis to fit the evolution of science and technology more completely into the process of improvement of material well-being; and secondly, by estimating the value deducted, to provide risk management with a useful instrument of quantification, while at the same time yielding usable technological forecasts.

\section{A tool of Risk Management}

The studies published in this issue provide an invaluable guidance for any practical policy of Risk Management. They provide not only a quantitative and qualitative estimate of the damages but also suggest practical methods of preventing and reducing the risks. The future economic strategies aimed at the increase of wealth and welfare depend more and more on the control of such types of uncertainties.

Of course, studies of this kind are only first attempts which leaves plenty of room for improvements in method and for new quantitative estimates.

We believe, however, that this is unquestionably a major contribution to the work of all those who have to cope with the growing risks and uncertainties of the modern world. Relying on Risk Management and trying to assess the value deducted is one practical way of resisting the sometimes ingratiating but more usually blatant, demagogic attractions of the Scyllas and Charybdises of our times. 